\title{
Parenteral Nutrition Administration Leads to Specific Alterations in the Expression of Adipocytokines and Peroxisome Proliferator-Activated Receptors in a Rat Model
}

Journal of Parenteral and Enteral Nutrition Volume 35 Number 3 May 2011 329-336 (C) 2011 American Society for Parenteral and Enteral Nutrition $10.1177 / 0148607110381266$ http://jpen.sagepub.com hosted at http://online.sagepub.com

\author{
Yuko Tazuke ${ }^{1,2}$; Daniel Teitelbaum ${ }^{3}$; Masafumi Wasa ${ }^{1}$; \\ Masahiro Fukuzawa $^{1}$; Yasuhiko Iiboshi ${ }^{2}$; and Jiro Fujimoto ${ }^{2}$
}

Financial disclosure: none declared.

Background: Similar to metabolic syndrome, parenteral nutrition (PN) administration has also been associated with biologic abnormalities of glucose and lipids. Such complications include hyperglycemia, hypertriglyceridemia, liver dysfunction, and hepatobiliary complications. Because metabolic syndrome has been associated with altered expression of adipocytokines, and peroxisome proliferator-activated receptors (PPARs), the present study hypothesized that PN would also lead to alterations in adipocytokines and related gene abundances. Methods: Male Wister rats received either intravenous (IV) saline and chow (control) or PN. To determine the contribution of lipids to metabolic changes, the following 2 PN groups were studied: $\mathrm{PN}$ with IV lipid $(\mathrm{PN}+\mathrm{L})$ and $\mathrm{PN}$ without lipid (PN-L). Rats were studied after 7 days. Results: A marked increase in hepatic glycogen staining was found in the PN-L group, and conversely, a marked increase in hepatic lipid staining was observed in the $\mathrm{PN}+\mathrm{L}$ group. Both $\mathrm{PN}$ groups demonstrated a $30 \%$ increase in serum adiponectin levels in comparison to controls. In the liver, ACDC mRNA expression significantly increased (10\%-20\%), while ADIPOR 1 expression significantly declined in the PN groups compared with controls. PPAR expression significantly declined $(10 \%-30 \%)$ in the $\mathrm{PN}+\mathrm{L}$ group compared with controls. In contrast to metabolic syndrome, $\mathrm{PN}+\mathrm{L}$ led to a decrease in tumor necrosis factor $\alpha$ and interleukin 6 levels in the liver. Conclusions: The study shows that PN led to specific alterations in the abundance of adipocytokines and PPARs. These changes give critical insight into many of the metabolic derangements in lipid metabolism, which patients may experience with PN. (JPEN J Parenter Enteral Nutr. 201 1;35:329-336)

Keywords: parenteral nutrition; nutrition; liver disease; research and diseases; lipids; nutrition; chorestasis; steatosis; adiponectin; PPAR; metabolic syndrome

\section{Clinical Relevancy Statement}

The findings that parenteral nutrition (PN) administration with and without lipids led to specific histologic and biochemical changes in both the liver and adipose compartments suggest that newer strategies for PN administration are needed to avoid such negative side effects. Both changes have a close resemblance to metabolic syndrome, and normally they develop within a week of administration. These metabolic abnormalities in both glucose and lipids might therefore help to elucidate the etiology of PN-related complications.

From ${ }^{1}$ Osaka University Graduate School of Medicine, Osaka, Japan; ${ }^{2}$ Hyogo College of Medicine, Nishinomiya, Japan; and ${ }^{3}$ University of Michigan, Ann Arbor, Michigan.

Received for publication January 7, 2010; accepted for publication May 19, 2010.

Address correspondence to: Yuko Tazuke, Osaka University Graduate School of Medicine, Osaka, Japan; e-mail: tazuyan@ aol.com.

\section{Introduction}

Parenteral nutrition (PN) is useful for patients who cannot tolerate enteral intake. ${ }^{1}$ However, $\mathrm{PN}$ is associated several adverse problems, including the development of $\mathrm{PN}$-associated liver disease (PNALD), which can lead to liver dysfunction, hepatobiliary complications, cholestasis, and steatosis. ${ }^{2-3}$ PNALD is a devastating complication and is associated with an increased incidence of sepsis, higher mortality rates, and the potential to develop irreversible liver injury..$^{4-9}$ However, the mechanisms that lead to PNALD remain unknown. Rodent models of PN show a decline in MDR2 expression. ${ }^{10-11}$ MDR2 is a key factor that transports bile from the hepatocyte to the bile canaliculi, and this decline may be a contributing factor in the development of PNALD. Interestingly, a decline in the MDR2 expression has also been reported to correlate with changes in the expression of peroxisome proliferatoractivated receptors (PPARs). ${ }^{11}$ PPARs are a group of 3 nuclear receptor isoforms, PPAR- $\alpha$, PPAR- $\gamma$, and PPAR- $\delta$. PPARs play critical physiologic roles as lipid sensors and regulators of lipid metabolism. ${ }^{12}$ The upregulation of PPAR- $\alpha$ induces 
increased triglyceride (TG) levels and decreased high density lipoprotein (HDL) levels. ${ }^{13}$ PPAR- $\gamma$ is associated with insulin resistance. ${ }^{14} \mathrm{~A}$ mild down regulation of PPAR- $\gamma$ induces decreased TG levels and an increased expression of adiponectin. Adiponectin is an adipocyte-derived hormone that is present in plasma and sensitizes the organism to insulin as well as acts as an anti-inflammatory factor. In contrast, severe down-regulation of PPAR- $\gamma$ leads to increased TG levels and decreased adiponectin levels. More potent synthetic PPAR ligands, including fibrates and thiazolidinediones, can modulate MDR2 abundance ${ }^{15}$ and have proven effective for the treatment of dyslipidemia and diabetes. ${ }^{16}$ Because of these critical metabolic activities, PPARs have been identified as key factors in metabolic syndrome.

Metabolic syndrome is defined as abdominal obesity, dyslipidemia, proinflammatory cytokine state, and insulin resistance. ${ }^{17,18}$ Metabolic syndrome can lead to a number of clinical complications, including hyperglycemia, hypertriglyceridemia, hypertension, diabetes, cholestasis, steatosis, thrombosis, and infection. ${ }^{17}$ Importantly, adiponectin, other adipocytokines, and PPARs may be either upregulated or downregulated with metabolic syndrome,${ }^{19}$ whereby adiponectin levels are decreased in patients with visceral obesity, unlike other factors, which are typically increased by lipids in metabolic syndrome. Adiponectin in particular has attracted attention in the pathophysiology of metabolic syndrome. The action of adiponectin extends to the insulinsensitizing function, anti-inflammatory properties, and antiatherogenic function. ${ }^{20}$

Interestingly, some of the metabolic problems observed with the administration of PN have similarities to those observed in patients developing metabolic syndrome. Common to both conditions is a large intake of glucose and fat. It is also possible that the administration of lipids in PN solution may be a contributing factor to some of these metabolic derangements, as PN with lipids has been shown to increase hepatocyte apoptosis. ${ }^{21}$ The stimulation of lipid metabolicassociated genes such as PPARs may inhibit hepatic apoptosis. ${ }^{22}$ Other agonists of lipid metabolic-associated genes may, however, lead to an increase in hepatocyte apoptosis. ${ }^{23}$

The aim of this study was to test the hypothesis that PN administration would lead to metabolic abnormalities of glucose and lipids and subsequently lead to an altered abundance of adipocytokines and their related gene expression in a rat model. This study also investigated whether some or all of these PN-associated metabolic abnormalities are related to parenteral lipid administration.

\section{Materials and Methods}

\section{Animals}

The treatment of the rats and our study was approved by the Ethics Review Committee for Animal Experimentation of Osaka University School of Medicine in Osaka, Japan. Male Wister rats ( $\mathrm{n}=26$; weight range, 200-220 g), purchased from Clea Japan Co (Tokyo, Japan) were used. Rats were maintained in pathogen-free conditions in the animal facility. The experimental animals had free access to standard rat food (Oriental Yeast Co, Osaka, Japan) and tap water, while in their cages, and were acclimatized to standard conditions in the laboratory with approximately $40 \%$ to $60 \%$ humidity at room temperature of $23^{\circ} \mathrm{C}$. The rats were subjected to alternate 12-hour light/dark cycles.

\section{Experimental Protocols/Procedures}

After an overnight fast, the rats $(n=26)$ were anesthetized with the intraperitoneal injection of $90 \mathrm{mg} / \mathrm{kg}$ of ketamine. Catheterization and administration of PN was similar to that described previously. ${ }^{10-11,21,24}$ Briefly, the neck and interscapular regions were shaved and prepared in a sterile manner for catheterization. A silastic tube (inner diameter, 0.5 $\mathrm{mm}$; Kaneka Medix Co, Osaka Japan) was inserted through the right jugular vein. The catheter was tunneled subcutaneously and brought out through the skin of the midscapular region.

After catheterization, rats were maintained in individual metabolic cages and infused with normal saline in addition to standard laboratory rat chow and water ad libitum. After 24 hours, all rats were separated into 3 groups. The control group $(\mathrm{n}=5)$ received the same intravenous (IV) physiologic saline at $80 \mathrm{~mL} /$ day in addition to standard laboratory rat chow (ie, approximately $350 \mathrm{kcal} / 100 \mathrm{~g}[1,465 \mathrm{~kJ} / 100 \mathrm{~g}]$, crude protein $27 \%$, crude fat $5 \%$, crude ash $7 \%$, crude fiber $4 \%$, nitrogen free extract 55\%; Clea, Japan) and water ad libitum. The PN-lipid group $(\mathrm{n}=7)$ received a standard IV PN solution at $80 \mathrm{~mL} / \mathrm{d}$ without any enteral nutrition (EN). The PN solution contained a balanced mixture of glucose, amino acids, electrolytes, minerals, and vitamins, as previously described. ${ }^{25}$ In a separate group of rats, PN was administrated with IV fats $(\mathrm{PN}+\mathrm{L}$ group, $\mathrm{n}=9)$. To allow for a matched amount of energy delivery between the groups, $10 \%$ of glucose calories were exchanged for fats (Intralipos 10\%; Otsuka Pharmaceutical Co, Ltd, Tokyo, Japan) in the PN+L group (Table 1). The amount of nonprotein calories given was $220-230 \mathrm{kcal} / \mathrm{kg} / \mathrm{day}$ as glucose. ${ }^{25-26}$ Multivitamins and electrolytes also were included in the PN solutions. After 7 days of total continuous infusion, all mice were killed. Blood samples were collected aseptically from the inferior vena cava and centrifuged $\left(13,000 \mathrm{~g}\right.$ for 5 minutes at $\left.4^{\circ} \mathrm{C}\right)$, and thereafter plasma was collected. Liver and adipose tissue from mesenteric (visceral fat) specimens were obtained. The samples were preserved either with $10 \%$ buffered formaldehyde ( $10 \%$ formalin in phosphate buffer) for histologic examination, or immediately frozen in liquid nitrogen for mRNA extraction, protein, and lipid analyses. 
Table 1. The Composition of the Nutrients in 3 Groups

\begin{tabular}{lclcr}
\hline & Control (Standard Food) & & PN-L (in 100 mL) & PN+L (in 100 mL) \\
\hline Protein & $22 \%-23 \%$ & Glucose (g) & 15.7 & 14.1 \\
Lipid & $4.5 \%-5.5 \%$ & SAA (g) & 5.0 & 5.0 \\
Mineral mixture & $5.5 \%-6.0 \%$ & Nitrogen (g) & 0.79 & 0.79 \\
Soluble nonnitrogen & $54 \%-57 \%$ & Lipid (kcal) & 0 & 6.3 \\
Fiber & $3.0 \%$ & NPC (kcal) & 62.8 & 62.7 \\
Kcal/d & $50-60$ & NPC/N & 79.5 & 79.4 \\
$\mathrm{~kJ} / \mathrm{d}$ & $0.21-0.25$ & $\mathrm{~kJ} / \mathrm{d}$ & 0.277 & 0.277 \\
\hline
\end{tabular}

PN-L, parenteral nutrition without lipids; PN+L, parenteral nutrition with lipids; SAA, sulfur-containing amino acid; NPC, non-protein-calorie; N, nitrogen.

\section{Histologic Evaluation}

Portions of liver were fixed in neutral buffered formalin and sectioned at a thickness of 3 to $5 \mu \mathrm{m}$ using a microtome and were then stained with periodic acid-Schiff (PAS) reagent to detect glycogen, and Sudan III reagent to detect fat (including triglycerides, some protein-bound lipids, and lipoproteins).

\section{Assay of Adipocytokines (Adiponectin, Insulin, Leptin, TNF- $\alpha$, and IL-6)}

The abundance of adipocytokines (adiponectin, insulin, leptin, tumor necrosis factor [TNF]- $\alpha$, and interleukin [IL6]) in serum, liver, fat was measured by enzyme-linked immunosorbent assay (ELISA) following the manufacturer's instructions. The rat/mouse adiponectin ELISA Set (Cat.No.41073; Otsuka Co, Japan), the rat/mouse insulin ELISA Set (Morinaga, Japan), the rat/mouse leptin ELISA Set (Morinaga, Japan), the rat TNF- $\alpha$ ELISA Kit (Cat. No.ER3TNFA; Endogen, Rockford IL), and the rat IL-6 ELISA Kit (Cat.No.ER2IL6; Endogen) from BD Biosciences were used to quantify each adipocytokines. Duplicate serial dilutions were performed for each sample, consisting of liver or fat pulverized samples, and mean absorbencies were used to determine the concentrations of the cytokines in the samples, according to the standard.

\section{Gene Expression of ACDC, ADIPOR1, and PPARs}

Total RNA was extracted from each liver and fat specimen using a kit, (ISOGEN, NIPPON GENE, Tokyo, Japan), according to the manufacturer's guidelines. The RNA concentrations were measured spectrophotometrically at 260 $\mathrm{nm}$. For each sample, $1 \mathrm{mcg}$ of total RNA was used. Reverse transcription was carried out using the High Capacity cDNA Reverse Transcription Kit (Applied Biosystems, Foster City, CA), according to the manufacturer's guidelines. The primers and probes for real-time reverse transcription polymerase chain reaction (RT-PCR) were provided by Applied Biosystems as ready-to-use mixes. The product identification numbers of the mixes were adiponectin (ACDC, UniGene; Rn.24299, Cat.No.Rn.00595250_m1), adiponectin receptor (ADIPOR1, UniGene; Rn.14556, Cat.No.Rn.01114954_g1), PPAR- $\alpha$ (UniGene; Mm.212789, Cat.No.Mm00440937_m1), PPAR- $\delta$ (UniGene; Mm.328914, Cat.No.Mm.01305435_m1), PPAR- $\gamma$ (UniGene; Mm.3020, Cat.No.Mm.01184321_ $\mathrm{m} 1$ ), and Rat ACTB Endogenous Control (UniGene; Rn.4352931E, Cat.No.Rn.01463175_m1). RT-PCR was carried out by using the ABI PRISM 7900HT Sequence Detection System (Applied Biosystems). A housekeeping gene, $A C T B$, served as the endogenous control. The results were expressed as a ratio of the target gene to ACTB.

\section{Statistical Analysis}

Data are represented as the mean \pm standard deviation. Data analysis was performed using an unpaired $t$ test and 1 -way analysis of variance (ANOVA), with $P<.05$ considered significant. Post-hoc intergroup analysis was performed using the Bonferroni $t$ test.

\section{Results}

\section{Histologic Analysis With PAS for Glycogen Detection}

Figure 1 shows representative liver sections from control and experimental groups stained for glycogen. In Figure 1A, the liver section from a control rat shows a normal distribution of glycogen in hepatocytes. In the $\mathrm{PN}-\mathrm{L}$ group, rats received larger amounts of glucose to balance energy delivery and were noted to have a marked increase in hepatic glycogen granules (Figure 1B). Figure 1C represents the liver from a rat in the $\mathrm{PN}+\mathrm{L}$ group. This showed a marked reduction in glycogen granules, which was not different than controls.

\section{Histologic Analysis for Intrahepatic Lipids}

We next examined the presence and amount of intrahepatic lipid deposition. Liver from control rats showed a normal 


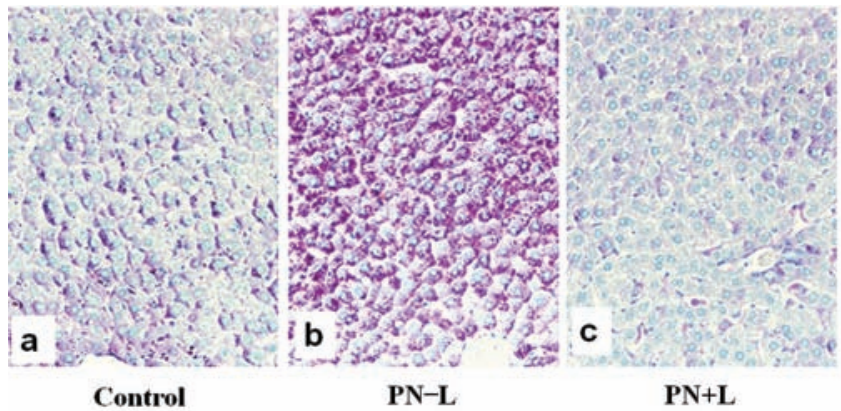

Figure 1. Representative hepatic sections stained with periodic acid-Schiff. (A) Slide from a control (chow fed) rat shows a normal distribution of glycogen in the hepatocytes. (B) Hepatic section from a rat treated with $\mathrm{PN}$-lipid, and shows a strong increase in glycogen granules. (C) Liver from a $\mathrm{PN}+\mathrm{L}$ group rat shows a reduction in glycogen granules to the level of controls. $\mathrm{PN}-\mathrm{L}$, parenteral nutrition without lipids; $\mathrm{PN}+\mathrm{L}$, parenteral nutrition with lipids.

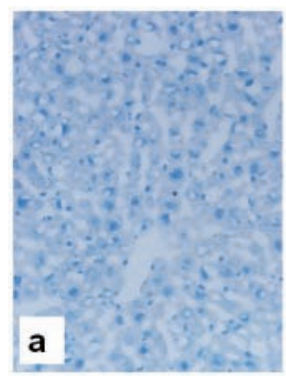

Control

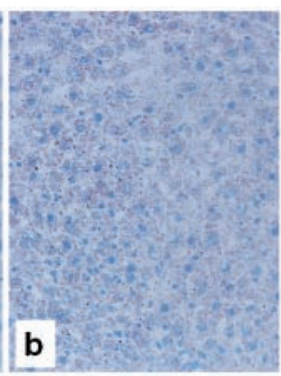

PN-L

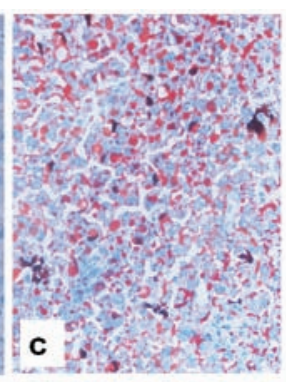

$\mathbf{P N}+\mathbf{L}$
Figure 2. Representative hepatic sections stained with Sudan III. (A) Slide from a control rat does not show any abnormal distribution of lipids in the liver. (B) Hepatic section of a rat in the PN-lipid group does not show any accumulation of lipid drops. (C) Hepatic section from a rat in the $\mathrm{PN}$-lipid group shows a strong increase in lipid droplets.

$\mathrm{PN}-\mathrm{L}$, parenteral nutrition without lipids; $\mathrm{PN}+\mathrm{L}$, parenteral nutrition with lipids.

distribution of hepatic lipids (Figure 2A). Similarly, hepatic sections from rats in the $\mathrm{PN}-\mathrm{L}$ group did not show any abnormal hepatic lipid deposition (Figure 2B). However, rats in the $\mathrm{PN}+\mathrm{L}$ group showed a much more intense distribution of lipid droplets in the liver compared with control and $\mathrm{PN}-\mathrm{L}$ groups (Figure 2C).

\section{Serum Adipocytokines}

Both PN groups showed a 30\% increase in serum adiponectin levels compared with controls (Figure 3). Serum insulin and leptin levels did not show any differences between the study groups (data not shown).

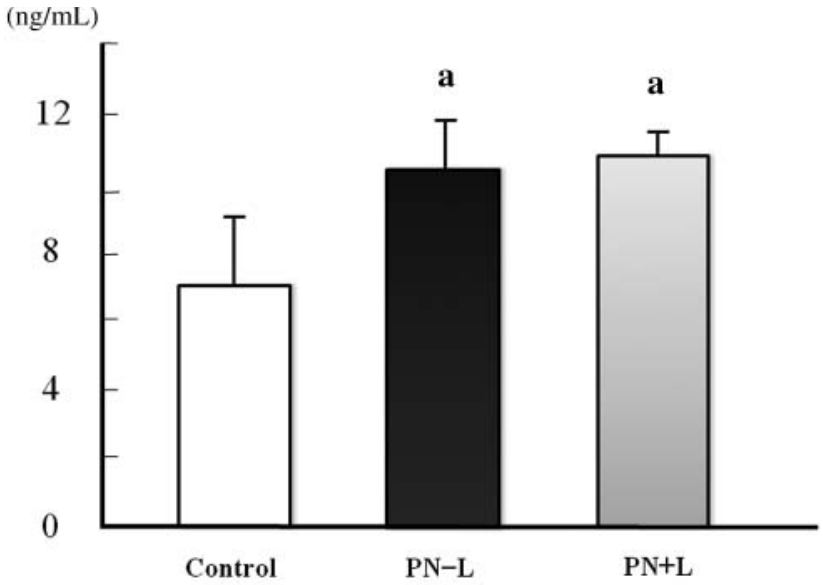

Figure 3. Concentration of serum adiponectin levels. Note adiponectin increased in both PN groups compared with the control group. Values are mean \pm standard deviation.

$\mathrm{PN}$, parenteral nutrition; $\mathrm{PN}-\mathrm{L}$, parenteral nutrition without lipids; $\mathrm{PN}+\mathrm{L}$, parenteral nutrition with lipids. ${ }^{a} P<.05$ vs control group.

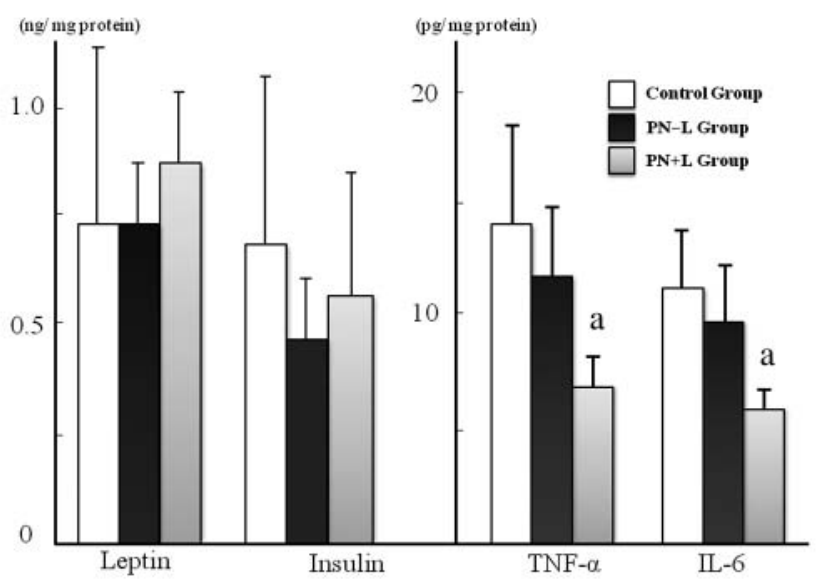

Figure 4. Hepatic adipocytokines insulin, leptin, TNF- $\alpha$, and IL-6 were assayed by ELISA. Insulin and leptin levels were relatively low in all groups. Abundance of TNF- $\alpha$ and IL-6 decreased in the PN+L group, compared with controls. ELISA, enzyme-linked immunosorbent assay; IL, interleukin; PN-L, parenteral nutrition without lipids; $\mathrm{PN}+\mathrm{L}$, parenteral nutrition with lipids; TNF- $\alpha$, tumor necrosis factor $\alpha$. ${ }^{\text {a }} \mathrm{P}<.05$ vs control group.

\section{Adipocytokine Expression in Liver and Fat}

Figure 4 shows the adipocytokine expression in the liver from each study group. Insulin and leptin levels were relatively low in all groups. Abundance of TNF- $\alpha$ and IL-6 were significantly decreased in the $\mathrm{PN}+\mathrm{L}$ group compared with the $\mathrm{PN}-\mathrm{L}$ and control groups. 


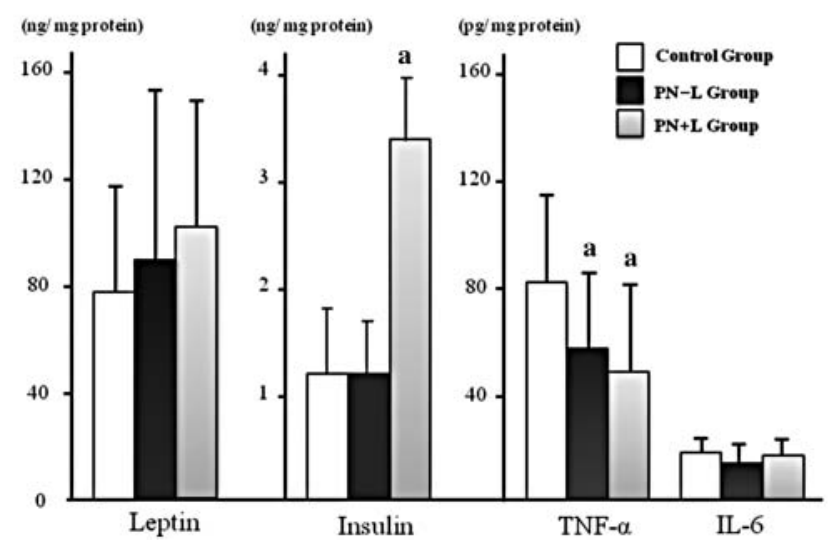

Figure 5. Fat adipocytokines insulin, leptin, TNF- $\alpha$, and IL-6 assayed by ELISA. Abundance of TNF- $\alpha$ decreased in both of PN groups compared with controls. The expression of insulin was relatively low in all groups, but increased in the $\mathrm{PN}+\mathrm{L}$ group compared to the other 2 groups.

ELISA, enzyme-linked immunosorbent assay; IL, interleukin; $\mathrm{PN}-\mathrm{L}$, parenteral nutrition without lipids; $\mathrm{PN}+\mathrm{L}$, parenteral nutrition with lipids; TNF- $\alpha$, tumor necrosis factor $\alpha$. ${ }^{a} P<.05$ vs control group.

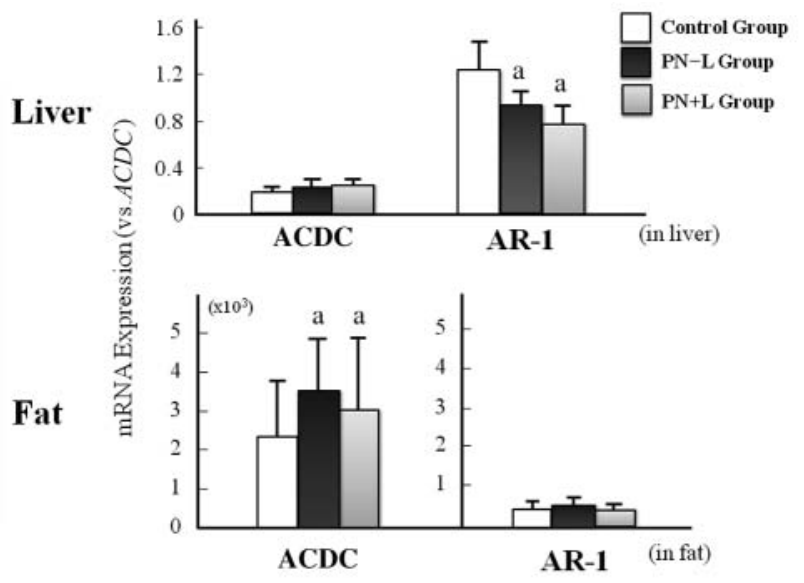

Figure 6. Hepatic ADIPOR1 (AR-1) abundance (top panels) significantly decreased $(10 \%-30 \%)$ in both $\mathrm{PN}$ groups. The expressions of $A C D C$ gene was $10^{4}$-fold stronger in the fat than the liver. Expression of $A C D C$ in fat tissue increased in both PN groups (bottom panels) compared with controls.

$A C D C$, adiponectin encoding gene; AR-1, adiponectin receptor gene 1; PN, parenteral nutrition; $\mathrm{PN}-\mathrm{L}$, parenteral nutrition without lipids; $\mathrm{PN}+\mathrm{L}$, parenteral nutrition with lipids. ${ }^{\mathrm{a}} \mathrm{P}<.05$ vs control group.

Figure 5 shows adipocytokine expression in fat tissue. Leptin was strongly expressed in fat. TNF- $\alpha$ levels were decreased in both PN groups compared with the control group. IL-6 levels did not significantly change between groups. Insulin levels were relatively low in all groups, but compared with the other 2 groups was significantly increased in the $\mathrm{PN}+\mathrm{L}$ group.

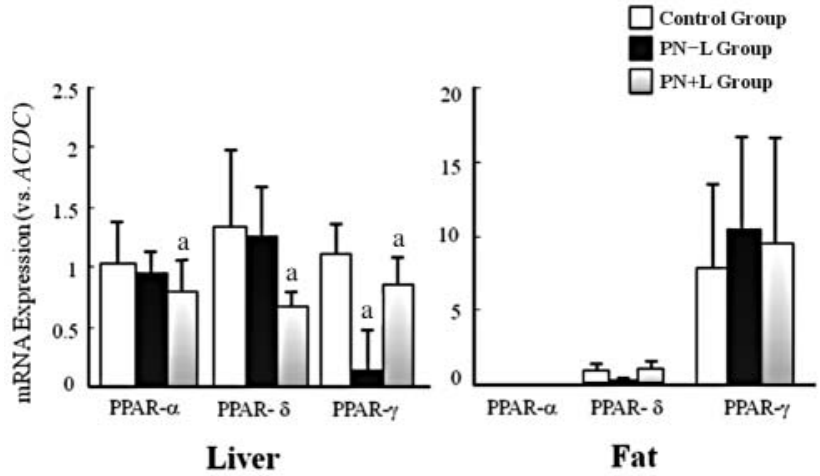

Figure 7. Hepatic PPARs (PPAR- $\alpha$, PPAR- $\delta$, and PPAR- $\gamma$ ) expression significantly declined in the $\mathrm{PN}+\mathrm{L}$ group compared to controls. In the PN-L group, hepatic PPAR- $\gamma$ abundance also decreased significantly compared with controls. In fat tissue, only PPAR- $\gamma$ was noted to be strongly detected in all groups but did not vary significantly between groups.

ACTB, $\beta$-actin; mRNA, messenger RNA; PN-L, parenteral nutrition without lipids; PN+L, parenteral nutrition with lipids; PPAR, peroxisome proliferator-activated receptor.

${ }^{\mathrm{a}} P<.05$ vs control group.

\section{mRNA Abundance of Adiponectin (ACDC) and the Receptor Gene (ADIPOR1) in Liver and Fat}

To further understand the control of lipid metabolism with PN, the regulatory control factors for adipocytokines were examined (Figure 6). Adiponectin is encoded by the adipocyte $\mathrm{Clq}$ and collagen domain containing (ACDC) gene. The expression of the ACDC gene was 104-fold stronger in fat compared with the liver. The abundance of ACDC in the fat was significantly increased (10\%-20\%) in both PN groups in comparison with controls. The adiponectin receptor ADIPOR 1 mediates PPAR- $\alpha$ ligand activities as well as fatty acid oxidation and glucose uptake by adiponectin. ADIPOR 1 (AR-1) expression was significantly decreased $(10 \%-30 \%)$ in the liver in both PN groups.

\section{mRNA Abundance of PPAR}

\section{Genes in Liver and Fat}

As the PPAR family can modulate adiponectin levels, the abundances of these family members were next examined in liver and fat tissues (Figure 7). In fat tissue, PPAR- $\gamma$ expression was more strongly expressed than other PPAR genes (PPAR- $\alpha$ and PPAR- $\delta$ ). In the liver, PPAR- $\alpha$ and PPAR- $\delta$ expression significantly declined $(10 \%-30 \%)$ in the $\mathrm{PN}+\mathrm{L}$ group compared with controls. Conversely, PPAR- $\gamma$ expression in the liver significantly decreased in both PN groups compared with controls. However, the decline in the $\mathrm{PN}-\mathrm{L}$ group was several times greater than the $\mathrm{PN}+\mathrm{L}$ group. 


\section{Discussion}

The clinical spectrum of PNALD includes cholestasis, steatosis, cholelithiasis, sepsis, hepatic fibrosis, biliary cirrhosis, the development of portal hypertension, and liver failure..$^{27-28}$ However, the pathogenesis of these disorders remains unclear. The present study utilized $2 \mathrm{PN}$ rodent models to better study this question. The histologic findings of the liver exhibited glycogen accumulation in the $\mathrm{PN}-\mathrm{L}$ group and a marked increase in hepatic lipids in the $\mathrm{PN}+\mathrm{L}$ group. Both changes were quite distinct from chow-fed rats which indicates the development of a vesicular fatty liver-findings that may mimic changes seen in clinical patients. Such a similar pattern may be seen in patients suffering from metabolic syndrome. ${ }^{29-30}$ The early steatotic development of fatty liver may be because of various mechanisms, including increased lipid uptake, increased lipid transport to the liver, increased lipid synthesis, impaired transport from liver, and the decreased oxidation of fatty acids. ${ }^{30-31}$ In addition, excessive glucose administration may lead to steatosis attributed to hepatic glycogen accumulation. Excessive or continuous energy delivery results in hyperinsulinemia, which suppresses fatty acid oxidation and the acceleration of fatty acid synthesis from glucose..$^{32}$ Although clearly distinct processes, such metabolic changes may occur either with PN or in metabolic syndrome. Recently, long-term PN has been reported as one of the risk factors for the development of nonalcoholic steatohepatitis (NASH) ${ }^{33} \mathrm{~A}$ likely contributor to NASH in these patients may be continuous administration of $\mathrm{PN}$, which leads to hepatic accumulation of glycogen and lipids because of an inability to adequately metabolize base substrates.

Generally, lipids should be taken into the lymphatic reticular systems via the intestinal route. However, the direct IV infusion of fats via PN might result in stacked lipid drops in peripheral capillaries, including the liver, similar to that seen in Figure 2C. The mechanisms that cause these changes may relate to an altered regulation of the genes that modulate fat in the liver. This prompted us to pursue these subsequent investigations.

Adiponectin is a key molecule in obesity-related metabolic syndrome and a novel adipocytokine. Its abundance negatively correlates with the parameters of metabolic syndrome, where a lack of adiponectin may accelerate steatohepatitis as well as result in increased serum TNF- $\alpha$ expression. ${ }^{20}$ Interestingly, increased adiponectin expression was detected in both PN study models. Such an increase may be a corrective attempt to adjust for the constant delivery of substrate to the liver. The increased expression of adiponectin found in this study is clearly different from those changes found in metabolic syndrome, and thus our PN model is distinct from many of the aspects of this syndrome. An increase in adiponectin has been reported in models of carbon tetrachloride-treated mice ${ }^{34}$ and in human patients with liver cirrhosis. ${ }^{35-38}$ The adiponectin receptor ADIPOR 1 actually decreased in both PN groups. The lack

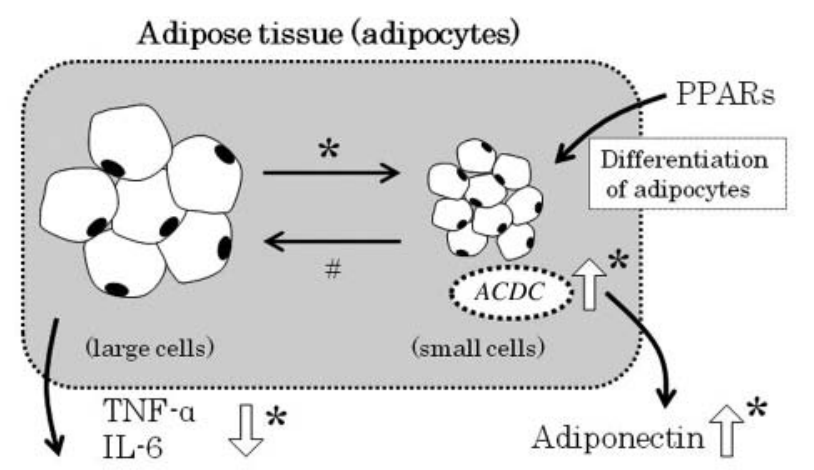

\section{* : Dieting/Cachexia without any stress / Standard PN \# : Metabolic syndrome/Obesity/Stress/Excessive PN}

Figure 8. Summary of the regulatory processes that are altered by $\mathrm{PN}$ in adipose tissue. Large adipocytes change to the small cells, which secrete adiponectin, under dieting, cachexia, standard PN, or antimetabolic conditions. Conversely, the number of large cells increase with obesity, stress, or excessive PN and secrete TNF- $\alpha$ and IL- 6 .

$A C D C$, adiponectin encoding gene; IL, interleukin; PN, parenteral nutrition; PPAR, peroxisome proliferator-activated receptor; TNF- $\alpha$, tumor necrosis factor $\alpha$.

*Dieting, cachexia without any stress, standard PN.

${ }^{\#}$ Metabolic syndrome, obesity, stress, or excessive PN.

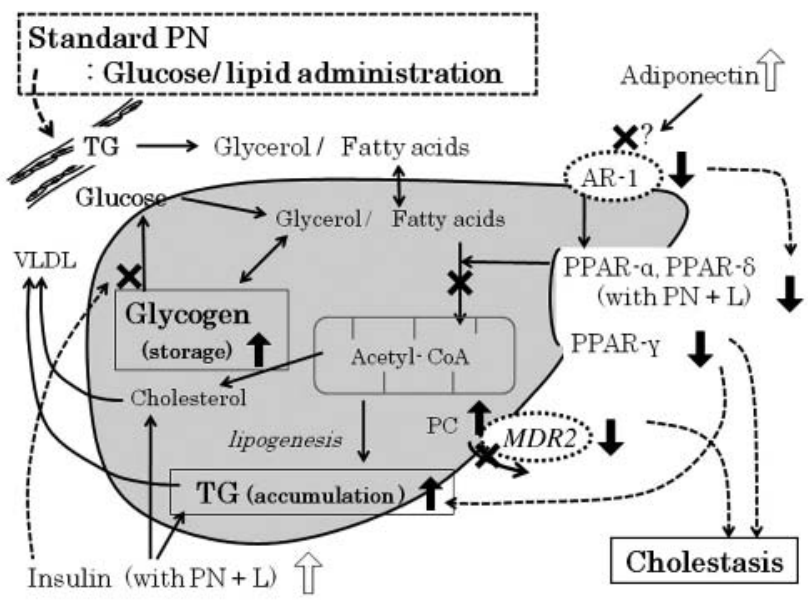

Figure 9. Summary of the regulatory processes that are altered by $\mathrm{PN}$ in liver. PN administration decreased AR-1/PPARs/ MDR2 expressions, in spite of the increased adiponectin levels. It might lead the metabolic suppressions of fatty acids in liver and the decline of PC secretion into bile. Moreover, increased insulin levels (with $\mathrm{PN}+\mathrm{L}$ ) might lead to the storage of glycogen in liver. ACETLY COA, acetyl coenzyme a; MDR2, multidrug-resistance 2 P-glycoprotein; VLDL, very low-density lipoprotein; PN, parenteral nutrition; PC, phospholipids (phosphatidyl choline); AR-1, adiponectin receptor gene 1; PPARs, peroxisome proliferator-activated receptors; $\mathrm{PN}+\mathrm{L}$, parenteral nutrition with lipids; TG, triglycerides. 
of a synthetic balance between increased serum adiponectin levels and decreased hepatic ADIPOR 1 expression ${ }^{39-40}$ might be characterized as a key element in the metabolic abnormality in our PN models (Figures 8 and 9). In other words, the loss of receptor expression may lead to inadequate adiponectin action despite the increased serum levels. Signaling via $A D I P O R 1$ helps to mediate PPAR action.

Decreased PPAR abundance may lead to functional insulin resistance. ${ }^{41}$ Signaling via PPAR- $\gamma$ ligand increases expression and plasma concentrations of adiponectin. ${ }^{42}$ The current study showed decreased PPAR- $\gamma$ expression in the liver of our PN animals, particularly in the PN-L group. PPAR- $\gamma$ is known as a thrifty gene. ${ }^{43,44}$ The stimulation of such genes results in energy storage, while the absence of the gene affects energy consumption. Thus, the observed decline in PPAR- $\gamma$ might be one of the mechanisms responsible for the glycogen/lipid accumulation in the liver of the PN group animals (Figures 1 and 2).

The PN models in the present paper showed significantly decreased expression of TNF- $\alpha$ compared with controls. Generally, TNF- $\alpha$ is produced more in insulin-resistant conditions and dose-dependently reduces the expression of adiponectin in adipocytes by suppressing its promoter activity. ${ }^{42}$ Interestingly, the percentage of monocytes producing TNF- $\alpha$ and IL-6 after LPS stimulation are lower in infants on PN than both control infants and adults. ${ }^{45}$ This may explain one of the mechanisms responsible for the reduced inflammatory response to the bacterial challenge in infants on $\mathrm{PN}$ in comparison with enterally fed infants or adults. ${ }^{45}$ In addition, decreased TNF- $\alpha$ and IL-6 levels are characteristic of patients with cirrhosis, which has also been shown to correlate with elevated circulating adiponectin levels. ${ }^{35}$ The $\mathrm{PN}+\mathrm{L}$ model studied here might also resemble this situation because of the decreased TNF- $\alpha$ and IL-6 levels and increased adiponectin level. The precise relevance of these altered cytokines on the changes in adiponectin and downstream factors will require further work in the future. A summary of the metabolic and regulatory mechanisms are shown in Figures 8 and 9. Despite end-point hepatic changes similar to those observed in metabolic syndrome, other regulatory differences are also highlighted in these figures.

In conclusion, this study showed that PN led to specific alterations in the expressions of metabolic adipocytokines and PPARs in the rat model. PN administration with and without fat led to specific histologic and biochemical changes in the liver and adipose compartments of the rat. These metabolic abnormalities in both glucose and lipids might therefore help to elucidate the etiology of PN-related metabolic complications. The results also may suggest that newer strategies of PN administration are needed to avoid such derangements.

\section{Acknowledgments}

We gratefully acknowledge the technical assistance of Kazuko Aizawa and Keiko Mitani and the excellent editorial assistance of the Editorial Board of the Japanese Society for Surgical Metabolism and Nutrition.

\section{References}

1. Dudrick SJ. Early developments and clinical applications of total parenteral nutrition. JPEN J Parenter Enteral Nutr. 2003;27:291-299.

2. Sandhu IS, Jarvis C, Everson GT. Total parenteral nutrition and cholestasis. Clin Liver Dis. 1999;3:489-508,viii.

3. Teitelbaum DH. Parenteral nutrition-associated cholestasis. Curr Opin Pediatr. 1997;9:270-275.

4. Beath SV, Davies P, Papadopoulou A, et al. Parenteral nutritionrelated cholestasis in postsurgical neonates: multivariate analysis of risk factors. J Pediatr Surg. 1996;31:604-606.

5. Gimmon Z. Total parenteral nutrition-associated cholestasis. J Pediatr Gastroenterol Nutr. 1986;5:831.

6. Capron JP, Gineston JL, Herve MA, Braillon A. Metronidazole in prevention of cholestasis associated with total parenteral nutrition. Lancet. 1983;26:446-447.

7. Kubota A, Yonekura T, Hoki M, et al. Total parenteral nutritionassociated intrahepatic cholestasis in infants: 25 years' experience. J Pediatr Surg. 2000;35:1049-1051.

8. Spiliotis JD, Kalfarentzos F. Total parenteral nutrition-associated liver dysfunction. Nutrition. 1994;10:255-260.

9. Moss RL, Amii LA. New approaches to understanding the etiology and treatment of total parenteral nutrition-associated cholestasis. Semin Pediatr Surg. 1999;8:140-147.

10. Tazuke Y, Kiristioglu I, Heidelberger KP, Eisenbraun MD, Teitelbaum DH. Hepatic P-glycoprotein changes with total parenteral nutrition administration. JPEN J Parenter Enteral Nutr. 2004;28:1-6.

11. Tazuke Y, Teitelbaum DH. Alteration of canalicular transporters in a mouse model of total parenteral nutrition. J Pediatr Gastroenterol Nutr. 2009;48:193-202.

12. Lee CH, Olson P, Evans RM. Minireview: lipid metabolism, metabolic diseases, and peroxisome proliferator-activated receptors. Endocrinology. 2003;144:2201-2207.

13. Srivastava RA, Jahagirdar R, Azhar S, Sharma S, Bisgaier CL. Peroxisome proliferator-activated receptor-alpha selective ligand reduces adiposity, improves insulin sensitivity and inhibits atherosclerosis in LDL receptor-deficient mice. Mol Cell Biochem. 2006;285:35-50.

14. Yamauchi T, Kadowaki T. The molecular mechanisms by which PPAR gamma/RXR inhibitors improve insulin resistance [in Japanese]. Nippon Rinsho. 2001;59:2245-2254.

15. Kok T, Bloks VW, Wolters H, et al. Peroxisome proliferator-activated receptor alpha (PPARalpha)-mediated regulation of multidrug resistance 2 (Mdr2) expression and function in mice. Biochem J. 2003; 369:539-547.

16. Auwerx J, Schoonjans K, Fruchart JC, Staels B. Regulation of triglyceride metabolism by PPARs: fibrates and thiazolidinediones have distinct effects. J Atheroscler Thromb. 1996;3:81-89.

17. Matsuzawa Y, Funahashi T, Kihara S, Shimomura I. Adiponectin and metabolic syndrome. Arterioscler Thromb Vasc Biol. 2004;24:29-33.

18. Esposito K, Giugliano D. The metabolic syndrome and inflammation: association or causation? Nutr Metab Cardiovasc Dis. 2004;14: 228-232.

19. Matsuzawa Y, Shimomura I, Kihara S, Funahashi T. Importance of adipocytokines in obesity-related diseases. Horm Res. 2003;60:56-59.

20. Fukushima J, Kamada Y, Matsumoto H, et al. Adiponectin prevents progression of steatohepatitis in mice by regulating oxidative stress and Kupffer cell phenotype polarization. Hepatol Res. 2009;39:724-738.

21. Tazuke Y, Drongowski RA, Btaiche I, Coran AG, Teitelbaum DH. Effects of lipid administration on liver apoptotic signals in a mouse model of total parenteral nutrition (TPN). Pediatr Surg Int. 2004;20:224-228. 
22. Hasmall SC, West DA, Olsen K, Roberts RA. Role of hepatic nonparenchymal cells in the response of rat hepatocytes to the peroxisome proliferator nafenopin in vitro. Carcinogenesis. 2000;21:2159-2165.

23. Goll V, Viollon-Abadie C, Nicod L, Richert L. Peroxisome proliferators induce apoptosis and decrease DNA synthesis in hepatoma cell lines. Hum Exp Toxicol. 2000; 19:193-202.

24. Tazuke Y, Wildhaber BE, Yang H, Washburn J, Teitelbaum DH. Total parenteral nutrition leads to alteration of hepatocyte cell cycle gene expression and proliferation in the mouse. Dig Dis Sci. 2007;52:920-930.

25. Tazuke Y, Wasa M, Shimizu Y, Wang HS, Okada A. Alanylglutamine-supplemented parenteral nutrition prevents intestinal ischemia-reperfusion injury in rats. JPEN J Parenter Enteral Nutr. 2003;27:110-115.

26. Morikawa N, Hagane K, Yokoyama J, Ishida H, Kitajima M. Effects of cyclic total parenteral nutrition on circadian rhythmicity of serum parameters, organ weight and histological findings of liver, kidney, and lung in rats. JSPS. 1995;31:577-588.

27. Kelly DA. Liver complications of pediatric parenteral nutritionepidemiology. Nutrition. 1998;14:153-157.

28. Briones ER, Iber FL. Liver and biliary tract changes and injury associated with total parenteral nutrition: pathogenesis and prevention. J Am Coll Nutr. 1995;14:219-228.

29. Hall RI, Grant JP, Ross LH, Coleman RA, Bozovic MG, Quarfordt SH. Pathogenesis of hepatic steatosis in the parenterally fed rat. J Clin Invest. 1984;74:1658-1668.

30. Wang H, Khaoustov VI, Krishnan B, et al. Total parenteral nutrition induces liver steatosis and apoptosis in neonatal piglets. J Nutr. 2006; 136:2547-2552.

31. Zambrano E, El-Hennawy M, Ehrenkranz RA, Zelterman D, ReyesMugica M. Total parenteral nutrition induced liver pathology: an autopsy series of 24 newborn cases. Pediatr Dev Pathol. 2004;7: 425-432.

32. Wanless IR, Lentz JS. Fatty liver hepatitis (steatohepatitis) and obesity: an autopsy study with analysis of risk factors. Hepatology. 1990;12:1106-1110.

33. Tanaka Y, Yagi M. Pathogenesis of hepatobiliary dysfunction caused by total parenteral nutrition. Igaku No Ayumi (Jap). 2006;18:409-412.
34. Yoda-Murakami M, Taniguchi M, Takahashi K, et al. Change in expression of GBP28/adiponectin in carbon tetrachloride-administrated mouse liver. Biochem Biophys Res Commun. 2001;285:372-377.

35. Tietge UJ, Boker KH, Manns MP, Bahr MJ. Elevated circulating adiponectin levels in liver cirrhosis are associated with reduced liver function and altered hepatic hemodynamics. Am J Physiol Endocrinol Metab. 2004;287:E82-89.

36. Tacke F, Wustefeld T, Horn R, et al. High adiponectin in chronic liver disease and cholestasis suggests biliary route of adiponectin excretion in vivo. J Hepatol. 2005;42:666-673.

37. Sohara N, Takagi H, Kakizaki S, Sato K, Mori M. Elevated plasma adiponectin concentrations in patients with liver cirrhosis correlate with plasma insulin levels. Liver Int. 2005; 25:28-32.

38. Liu CJ, Chen PJ, Lai MY, et al. High serum adiponectin correlates with advanced liver disease in patients with chronic hepatitis B virus infection. Hepatol Int. 2009;3:364-370.

39. Inukai K, Nakashima Y, Watanabe M, et al. Regulation of adiponectin receptor gene expression in diabetic mice. Am J Physiol Endocrinol Metab. 2005;288:E876-882.

40. Yamauchi T, Nio Y, Maki T, et al. Targeted disruption of AdipoR1 and AdipoR2 causes abrogation of adiponectin binding and metabolic actions. Nat Med. 2007;13:332-339.

41. Haluzik MM, Lacinova Z, Dolinkova M, et al. Improvement of insulin sensitivity after peroxisome proliferator-activated receptor-alpha agonist treatment is accompanied by paradoxical increase of circulating resistin levels. Endocrinology. 2006; 147:4517-4524.

42. Maeda N, Takahashi M, Funahashi T, et al. PPARgamma ligands increase expression and plasma concentrations of adiponectin, an adipose-derived protein. Diabetes. 2001;50:2094-2099.

43. Hara K, Kubota N, Tobe K, et al. The role of PPARgamma as a thrifty gene both in mice and humans. Br J Nutr. 2000;84: S235-S239.

44. Auwerx J. PPARgamma, the ultimate thrifty gene. Diabetologia. 1999;42:1033-1049.

45. Cruccetti A, Pierro A, Uronen H, Klein N. Surgical infants on total parenteral nutrition have impaired cytokine responses to microbial challenge. J Pediatr Surg. 2003;38:138-142. 